\title{
Plasmodium falciparum isolates from southern Ghana exhibit polymorphisms in the SERCA-type PfATPase6 though sensitive to artesunate in vitro
}

\author{
Bethel Kwansa-Bentum ${ }^{1,2}$, Irene Ayi ${ }^{2}$, Takashi Suzuki ${ }^{1,2}$, Joseph Otchere ${ }^{2}$, Takashi Kumagai ${ }^{1}$, William K Anyan², \\ Joseph HN Osei ${ }^{2}$, Hiroko Asahi', Michael F Ofori ${ }^{3}$, Nobuaki Akao ${ }^{1}$, Michael D Wilson ${ }^{2}$, Daniel A Boakye ${ }^{2}$ and \\ Nobuo Ohta ${ }^{1 *}$
}

\begin{abstract}
Background: In 2005, Ghana replaced chloroquine with artemisinin-based combination therapy as the first-line treatment for uncomplicated malaria. The aim of this work was to determine for the first time, polymorphisms in the putative pfATPase6 and pftctp, pfmdr1, pfcrt genes in Ghanaian isolates, particularly at a time when there is no report on artemisinin resistance in malaria parasites from Ghana. The sensitivity of parasite isolates to anti-malaria drugs were also evaluated for a possible association with polymorphisms in these genes.
\end{abstract}

Methods: The prevalence of point mutations in the above Plasmodium falciparum genes were assessed from filter-paper blood blot samples by DNA sequencing. In vitro drug sensitivity test was carried out on some of the blood samples from volunteers visiting hospitals/clinics in southern Ghana using a modified version of the standard WHO Mark III micro-test.

Results: All successfully tested parasite isolates were sensitive to artesunate; while 19.4\%, 29.0\% and 51.6\% were resistant to quinine, amodiaquine and chloroquine respectively. The geometric mean of $\mathrm{IC}_{50}$ value for artesunate was $0.73 \mathrm{nM}(95 \% \mathrm{Cl}, 0.38-1.08)$, amodiaquine $30.69 \mathrm{nM}(95 \% \mathrm{Cl}, 14.18-47.20)$ and chloroquine $58.73 \mathrm{nM}(95 \% \mathrm{Cl}$, 38.08-79.38). Twenty point mutations were observed in pFATPase6 gene, with no L263E and S769N. All mutations found were low in frequency, except D639G which was observed in about half of the isolates but was not associated with artesunate response $(p=0.42)$. The pftctp gene is highly conserved as no mutation was observed, while CVIET which is chloroquine-resistant genotype at codon 72-76 of the pfcrt gene was identified in about half of the isolates; this was consistent with chloroquine $I_{50}$ values $(p=0.001)$. Mutations were present in pfmdr1 gene but were not associated with artemisinin response $(p=1.00)$.

Conclusion: The pfATPase6 gene is highly polymorphic with D639G appearing to be fixed in Ghanaian isolates. These may just be spontaneous mutations as all parasite isolates that were tested displayed satisfactory in vitro response to artesunate. However, there is no improvement in susceptibility of the parasites to chloroquine five years after its proscription.

\section{Background}

Malaria remains a major public health concern in the world decades after Laveran discovered its causative agent in 1880. An estimated 247 million clinical cases occur every year across the globe, with about 881,000 deaths annually [1]. This quandary from malaria is partly

\footnotetext{
* Correspondence: matata.vip@tmd.ac.jp

${ }^{1}$ Section of Environmental Parasitology, Department of International Health Development, Tokyo Medical and Dental University, 5-45 Yushima 1-chome, Bunkyo-ku, Tokyo 113-8519, Japan

Full list of author information is available at the end of the article
}

due to the emergence and spread of Plasmodium falciparum parasites that are resistant to conventional anti-malaria drugs in almost all endemic countries $[2,3]$. Artemisinin derivatives, which are fast acting and kill all stages including young gametocytes of multi-drug resistant malaria parasites $[4,5]$, have been recommended by the World Health Organization (WHO) in the form of combination therapy for the treatment of uncomplicated malaria to enhance its therapeutic efficacy as well as

\section{(Ciomed Central}


delay any possible resistance development in the human malaria parasite [6].

Studies in China, Thailand and Cambodia where oral artemisinin-based monotherapies have long been used, reported on reduced susceptibility to artemisinin derivatives in some malaria parasites [7-9]. Due to the fact that multi-drug resistant parasites originated from this area [10], diligent surveillance aimed at monitoring susceptibility of malaria parasites to artemisinin derivatives and the partner drugs in endemic areas is prudent. Pieces of evidence demonstrate that the sarco-endoplasmic reticulum calcium-dependent (SERCA) ATPase protein encoded by pfATPase 6 and the translationally controlled tumour protein (TCTP) encoded by pftctp are involved in artemisinin activity $[11,12]$.

Uhlemann et al [13] in their study observed that L263E replacement in pfATPase6 gene abolishes inhibition of artemisinins in $P$. falciparum. A subsequent study in French Guiana revealed that $\mathrm{S} 769 \mathrm{~N}$ mutation in $p f A T$ Pase6 was associated with high artemether $\mathrm{IC}_{50}$ values [14]. In this same study, a combination of two mutations E431K and A623E in a clinical isolate from Senegal showed considerable increase in artemether $\mathrm{IC}_{50}$ [14], suggestive that these point mutations could be used in molecular monitoring of artemisinin derivatives to complement continuing in vitro surveillance. Until recently, it was thought that few mutations are present in the pfATPase6 gene as some studies have revealed polymorphisms in this putative gene even though their roles are not known $[15,16]$. Related studies have averred that while mutant haplotypes of $p f m d r 1$ and $p f c r t$ genes in some isolates conferred chloroquine resistance, they however increase parasite susceptibility to artemisinin derivatives $[17,18]$.

In the year 2005, Ghana deployed artemisinin-based combination therapy (ACT) as the first-line treatment for malaria [19]; however, oral artemisinin-based monotherapies are also registered, and in an uncontrolled use by the general public [20]. In spite of this, there is no report of suspected artemisinin resistance in $P$. falciparum isolates from Ghana yet, and no work has been carried out on the pfATPase6 gene as a molecular marker in Ghana. In this study, the susceptibility of $P$. falciparum parasites to artesunate, amodiaquine, chloroquine and quinine was evaluated in vitro for Ghanaian isolates; point mutations in the pfATPase6, pftctp, and pfmdr1 genes were also examined, creating a picture in time before any report of resistance, and if they could be associated with differential responses to the anti-malaria drugs above. In addition, the putative pfcrt gene which is implicated in chloroquine resistance was evaluated for the status quo in the parasite isolates after five years of chloroquine proscription, as in the case of Malawi [21,22].

\section{Methods}

\section{Study design and sites}

This hospital/clinic based cross-sectional survey was carried out from August to October 2010. Seven communities in southern Ghana, Okyereko, Buduatta, Nyanyano, Apam, Kasoa, Achimota and Maamobi were selected based on the availability of a health facility, and proximity to Noguchi Memorial Institute for Medical Research (NMIMR), Accra-Ghana in order to reduce logistical constraints so that the blood samples will be cultured within eight hours after collection from participants. These areas were also purposively selected based on the fact that there is an already established acquaintance with the health centres and the community members for other on-going projects in NMIMR. Malaria transmission in Ghana is stable throughout the year with seasonal variation, while studies have shown that entomological inoculation rate in some of the study communities range from 0-20 infective bites/ night $[23,24]$.

Study participants were recruited from persons attending health centres in the above-mentioned communities. They included those who have been diagnosed with uncomplicated malaria on the basis of their clinical symptoms and by Rapid Diagnostic Test (RDT) kit (Malaria Ag Pf/Pan, Immunochromatographic assay, BIOLINE SD Rapid Test, STANDARD DIAGNOSTICS, INC, Haryana, India). All RDT-positive participants were given the appropriate treatment by the doctors in the respective health centres immediately after sample collection.

\section{Sample collection}

A total of 146 strip filter-paper (ADVANTEC ${ }^{\circledR}$ ) blood blots as well as thick and thin blood films were prepared from both $P$. falciparum antigen positive and negative RDT tested volunteers using finger-pricked blood samples. The filter-paper blood blots were air-dried and packaged into individual re-sealable plastic bags with silica gel desiccant and kept at $4^{\circ} \mathrm{C}$ until ready for genomic DNA extraction, while the slides were stained with Giemsa to adjust parasitaemia before culturing. Plain vacutainer tubes that were used for the blood collection were coated with $0.5 \mathrm{ml} \mathrm{CPD-adenine} \mathrm{buffer,} \mathrm{an} \mathrm{anticoa-}$ gulant that can keep parasite isolates in good condition at room temperature for about eight hours [25]. Thirtyeight of the RDT-positives provided $3 \mathrm{ml}$ of venous blood samples which were aseptically collected into the above tubes. These were transported to the laboratory within four hours of collection for drug sensitivity tests.

\section{Drug sensitivity tests \\ Malaria parasite culture medium}

Hypoxanthine (SIGMA-Aldrich) solution was prepared by dissolving $54.4 \mathrm{mg}$ in $40 \mathrm{ml}$ distilled water with 
$0.6 \mathrm{ml}$ of $2 \mathrm{~N}-\mathrm{HCl}$. The basal medium consisted of RPMI 1640 with $2 \mathrm{mM}$ glutamine and $25 \mathrm{mM}$ HEPES (GIBCO-Invitrogen), with $25 \mu \mathrm{g} / \mathrm{ml}$ gentamicin solution (SIGMA-Aldrich). The culture medium comprised the above basal medium with 10\% Daigo's GF21 (Wako Pure Chemical Industries, Japan), supplemented with $150 \mu \mathrm{M}$ hypoxanthine and 5\% normal human serum. This complete culture medium was termed HGRPMI [26].

\section{Anti-malaria drugs tested}

The anti-malaria drugs tested were appropriately reconstituted. $10 \mathrm{mM}$ stock solution each of artesunate, amodiaquine dihydrochloride dihydrate $\left(\right.$ Sigma $\left.{ }^{(}\right)$and chloroquine diphosphate salt $\left(\operatorname{Sigma}^{\circledR}\right)$ were initially prepared in $5 \mathrm{ml}$ of phosphate buffered saline (PBS), while quinine $\left(\right.$ Sigma $\left.{ }^{\circledR}\right)$ was dissolved with $70 \%$ ethanol. Final drug concentrations ranged from $0.16-160 \mathrm{nM}$ for artesunate, $1.25-1280 \mathrm{nM}$ for amodiaquine and chloroquine, and 10-10,240 nM for quinine. These were prepared using HGRPMI. All reagents and culture medium were filter-sterilized through $0.2 \mu \mathrm{m}$ Acrodisc ${ }^{\circledR}$ filter membrane after preparation.

\section{Malaria parasite cultures}

The sensitivity of Ghanaian isolates to the anti-malaria drugs was assessed by a modification of the standard WHO Mark III micro-test [27]. In vitro assays were carried out on samples with parasitaemia $>0.3 \%$ by microscopy, within eight hours after collection. The blood samples in CPD-adenine buffer were washed three times with basal medium (RPMI 1640), removing the supernatant and white blood cell interface after every wash at $1800 \mathrm{rpm}$ for $6 \mathrm{~min}$. Erythrocytes were re-suspended at 1:1 volume in HGRPMI. The starting parasitaemia was adjusted to $0.3-2.0 \%$ when required, by the addition of fresh uninfected erythrocytes. Each well of a 96-well tissue culture plate was filled with $90 \mu \mathrm{l}$ drug solution of appropriate concentration plus $10 \mu \mathrm{l}$ parasite suspension of about $5 \%$ haematocrit $[28,29]$. Control wells (with parasitized or uninfected erythrocytes) contained drug-free medium. Cultures of $P$. falciparum FCR3/FMG (ATCC Catalogue No. 30932, Gambia) was used as a reference strain. The plates were incubated at $37^{\circ} \mathrm{C}$ in a gas mixture of $90 \% \mathrm{~N}, 5 \% \mathrm{CO}_{2}$ and $5 \% \mathrm{O}_{2}$ for $25-30$ hours.

\section{Growth inhibition assessment}

At the end of the incubation period, suspended medium was removed while the blood within each well was used to make thick smears on a microscope glass slide. These were air-dried, stained with Giemsa and examined under microscope at $\times 100$ magnification. The number of schizonts with three or more nuclei over a total of 200 asexual parasites was counted for each sample. All tests were done in duplicate; the drug concentration that inhibits schizogony by $50 \%\left(\mathrm{IC}_{50}\right)$ relative to the drug-free control samples of each $P$. falciparum isolate were estimated from dose-response curves by non-linear regression analysis using GraphPad Prism ${ }^{\circledR} 4.0$ software package (GraphPad Software, San Diego, CA, USA). Confidence interval (CI) at 0.05 significance level was calculated by GraphPad QuickCalcs (Descriptive statistics and CI of mean/Confidence interval of SD) using the same software as above. Pearson's correlation coefficient was used to calculate the correlation between parasite responses to the anti-malaria drugs after entering data into Microsoft Office Excel.

\section{Genomic DNA extraction}

Genomic DNA from each sample was obtained by boiling discs of the filter-paper blood blots in $150 \mu \mathrm{l}$ of 50 $\mathrm{mM} \mathrm{NaOH}$ with intermittent vortexing on a hot-plate $\left(95^{\circ} \mathrm{C} 30^{\prime}\right) ; 50 \mu \mathrm{l}$ of $1 \mathrm{M}$ Tris $\mathrm{HCl}$ was added to the recovered $50 \mu \mathrm{l}$ supernatant and the resulting mixture directly used as template for gene amplification [30].

\section{Sequencing of pfATPase6, pftctp, pfmdr1 and pfcrt genes}

Four specific overlapping oligonucleotide primer pairs (Table 1) were designed for genotyping significant portions of the coding sequence of pfATPase6 gene [GenBank:EF564342], while a pair of primer was sufficient for the relatively short pftctp gene [GenBank:DQ141561). Two pairs of primer were employed in sequencing portions of the pfmdr1 gene [GenBank:M29154.1] spanning codons 86, 184, 1034, 1042 and 1246; the first pair of primer targeted the first two codons whereas the second primer set were for the last three codons (Table 1). Two pairs of primer were also used in a nested PCR for sequencing portions of the pfcrt gene [GenBank:HQ287046] spanning codons 72-76 (Table 1). The $20 \mu \mathrm{l}$ PCR mix contained $10 \mu \mathrm{GoTaq}^{\circledR}$ Green Master Mix, primers at $0.5 \mu \mathrm{M}$ final concentration, and $1 \mu \mathrm{l}$ of DNA template. Cycling conditions for the various primer pairs are shown in Table 1. After gene amplification, the PCR products were run on $2 \%$ agarose gel electrophoresis to check for the correct bands; the products were directly sequenced with Big Dye terminator v3.1 Cycle Sequencing kit (Applied Biosystems, CA, USA), according to manufacturer protocol. Sequencing analyses were done in duplicates for all samples. The amplicon sequences were aligned with published data of the NCBI database by BLAST analysis.

For any association between molecular and in vitro results, a threshold $\mathrm{IC}_{50}$ was set by halving the mean $\mathrm{IC}_{50}$ for each drug and then assigning each sample at either boundary of these values. The resulting data were then plotted onto $2 \times 2$ contingency tables and calculated for significance using two-tailed Fisher's exact test [28]. 
Table 1 Oligonucleotide primers and PCR reaction conditions for SNPs detection in pfATPase6, pftctp, pfmdr1 and pfcrt genes

\begin{tabular}{|c|c|c|c|}
\hline $\begin{array}{l}\text { Gene } \\
\text { Primer pair }\end{array}$ & Sequence $5^{\prime} \Rightarrow 3^{\prime}$ & PCR product size (bp) & PCR reaction conditions \\
\hline \multicolumn{4}{|l|}{ pfATPase6 } \\
\hline atp6-1F & tcatctaccgctattgtatgtgg & 777 & $94^{\circ} \mathrm{C} 5^{\prime}$ followed by 40 cycles $\left(94^{\circ} \mathrm{C} 15^{\prime \prime} ; 55^{\circ} \mathrm{C} 30^{\prime \prime} ; 72^{\circ} \mathrm{C} 40^{\prime \prime}\right) ; 72^{\circ} \mathrm{C} 5^{\prime}$ \\
\hline atp6-1R & attcctcttagcaccactcct & & \\
\hline atp6-2F & tcaccaaggggtatcaacaa & 692 & $94^{\circ} \mathrm{C} 5^{\prime}$ followed by 40 cycles $\left(94^{\circ} \mathrm{C} 15^{\prime \prime} ; 55^{\circ} \mathrm{C} 30^{\prime \prime} ; 72^{\circ} \mathrm{C} 40^{\prime \prime}\right) ; 72^{\circ} \mathrm{C} 5^{\prime}$ \\
\hline atp6-2R & tggcataatctaattgctcttcc & & \\
\hline atp6-3F & atgtatagctgttgtaatcaacctaga & 822 & $94^{\circ} \mathrm{C} 5^{\prime}$ followed by 40 cycles $\left(94^{\circ} \mathrm{C} 15^{\prime \prime} ; 55^{\circ} \mathrm{C} 30^{\prime \prime} ; 72^{\circ} \mathrm{C} 40^{\prime}\right) ; 72^{\circ} \mathrm{C} 5^{\prime}$ \\
\hline atp6-3R & tcactatatggatcagcttcatca & & \\
\hline atp6-4F & ccagtacattgaatgaaaatg & 605 & $94^{\circ} \mathrm{C} 5^{\prime}$ followed by 40 cycles $\left(94^{\circ} \mathrm{C} 15^{\prime \prime} ; 55^{\circ} \mathrm{C} 30^{\prime \prime} ; 72^{\circ} \mathrm{C} 40^{\prime \prime}\right) ; 72^{\circ} \mathrm{C} 5^{\prime}$ \\
\hline atp6-4R & acgtggtggatcaataatacct & & \\
\hline \multicolumn{4}{|l|}{ pftctp } \\
\hline pftctp-1F & atgaaagtatttaaagacgtt & 462 & $94^{\circ} \mathrm{C} 5^{\prime}$ followed by 40 cycles $\left(94^{\circ} \mathrm{C} 15^{\prime \prime} ;\right.$ \\
\hline pftctp-1R & ttcttctcctttataataagaat & & $\left.50^{\circ} \mathrm{C} 30^{\prime \prime} ; 72^{\circ} \mathrm{C} 40^{\prime \prime}\right) ; 72^{\circ} \mathrm{C} 5^{\prime}$ \\
\hline \multicolumn{4}{|l|}{ pfmdr1 } \\
\hline mdr1-1F & tgaacaaaaagagtaccgctga & 823 & $94^{\circ} \mathrm{C} 5^{\prime}$ followed by 40 cycles $\left(94^{\circ} \mathrm{C} 15^{\prime \prime} ; 55^{\circ} \mathrm{C} 30^{\prime \prime} ; 72^{\circ} \mathrm{C} 1^{\prime}\right) ; 72^{\circ} \mathrm{C} 5^{\prime}$ \\
\hline mdr1-1R & ccataccaaaaaccgaatgc & & \\
\hline mdr1-2F & caagcggagttttgcattt & 1062 & $94^{\circ} \mathrm{C} 5^{\prime}$ followed by 40 cycles $\left(94^{\circ} \mathrm{C} 15^{\prime \prime} ; 55^{\circ} \mathrm{C} 30^{\prime \prime} ; 72^{\circ} \mathrm{C} 1^{\prime}\right) ; 72^{\circ} \mathrm{C} 5^{\prime}$ \\
\hline mdr1-2R & ttctctgtttttgtccacctga & & \\
\hline \multicolumn{4}{|l|}{ pfcrt } \\
\hline pfcrt-1'F & atggctcacgtttaggtgga & & $94^{\circ} \mathrm{C} 5^{\prime}$ followed by 40 cycles $\left(94^{\circ} \mathrm{C} 15^{\prime \prime} ; 55^{\circ} \mathrm{C} 15^{\prime \prime} ; 72^{\circ} \mathrm{C} 40^{\prime \prime}\right) ; 72^{\circ} \mathrm{C} 2^{\prime}$ \\
\hline pfcrt-2R & aaagcttcggtgtcgttc & & \\
\hline pfcrt-1F & tgtgctcatgtgtttaaactt & & $94^{\circ} \mathrm{C} 5^{\prime}$ followed by 25 cycles $\left(94^{\circ} \mathrm{C} 15^{\prime \prime} ; 48^{\circ} \mathrm{C} 30^{\prime \prime} ; 72^{\circ} \mathrm{C} 20^{\prime \prime}\right) ; 72^{\circ} \mathrm{C} 5^{\prime}$ \\
\hline pfcrt-2'R & ggaatagattctcttataaatcc & 282 & \\
\hline
\end{tabular}

The oligonucleotide primers were supplied by Greiner Bio-One Co., Ltd. Primer pairings of pfATPase6 gene, 1F \& $1 \mathrm{R}, 2 \mathrm{~F} \& 2 \mathrm{R}, 3 \mathrm{~F} \& 3 \mathrm{R}, 4 \mathrm{~F} \& 4 \mathrm{R}$ were used resulting in the corresponding PCR product sizes. For the pfcrt primers, nested PCR was carried out with 1 'F \& $2 R$ in the first reaction, followed by $1 F \& 2$ in the second reaction.

\section{Ethical clearance}

Participants consented by signing an agreement form after having been informed of the study purpose, with entry and exit criteria explained. Permission to conduct this research and ethical clearance were obtained from the Scientific and Technical Committee, and the Institutional Review Board both of the Noguchi Memorial Institute for Medical Research, Ghana (Certified Protocol Number: 035/09-10). This study also received ethical approval from Tokyo Medical and Dental University, Japan (Certificate Number 955).

\section{Results}

\section{In vitro drug sensitivity assessment}

Thirty-eight blood samples were phenotyped in vitro for their drug sensitivities, out of which 7 (18.4\%) failed the test due to poor growth or contamination (Table 2 \& Figure 1). No parasite isolate was resistant to artesunate, while 16/31 (51.6\%) were resistant to chloroquine. The highest $\mathrm{IC}_{50}$ value for artesunate was $3.6 \mathrm{nM}$, with geometric means as follows: artesunate, $0.73 \mathrm{nM}(95 \% \mathrm{CI}$, 0.38-1.08); amodiaquine, $30.69 \mathrm{nM}$ (95\% CI, 14.1847.20); chloroquine, $58.73 \mathrm{nM}$ (95\% CI, 38.08-79.38); quinine, $355.37 \mathrm{nM}$ (95\% CI, 250.48-460.26) (Table 2).
While Pearson's correlation coefficient between $\mathrm{IC}_{50}$ values of artesunate and amodiaquine was large (0.515), that of artesunate and chloroquine was medium, but were all statistically significant (Table 3 ). $\mathrm{IC}_{50}$ values for artesunate and chloroquine were 3.25 and $20.71 \mathrm{nM}$ respectively for the reference strain, FCR3/FMG.

\section{Prevalence of genetic polymorphisms in pfATPase6 and pftctp alleles}

After amplifying portions of the genes, agarose gel electrophoresis of PCR products indicated that the bands were of the expected sizes. Out of the 146 filter paper blood blots that were collected for genotyping, 68 parasite isolates were successfully amplified for pfATPase6 and 52 for pftctp genes; these included 34 isolates (all the successfully tested isolates plus three unsuccessful ones) that were used for drug sensitivity test (phenotyping). A total of twenty point mutations were found in pfATPase 6 gene (Table 4); analysis of this gene revealed a predominance of D639G in 34/68 (50\%), E431K in 7/68 (10.3\%), $\mathrm{D} 443 \mathrm{E}$ in $5 / 68$ (7.4\%) and M813Q in 5/68 (7.4\%) parasite isolates. Fisher's exact test revealed lack of association between D639G mutation and parasite response to artesunate $(p=0.423)$ (Table 5$)$. All other mutations found 
Table 2 In vitro drug sensitivity of Plasmodium falciparum isolates, $N=31$

\begin{tabular}{|c|c|c|c|c|c|}
\hline \multirow[t]{2}{*}{ Anti- malaria drug } & \multicolumn{2}{|c|}{ Number of isolates (\%) } & \multicolumn{3}{|c|}{$I C_{50}$ value $(\mathrm{nM})$} \\
\hline & Sensitive & Resistant* & Lowest/Highest & $\begin{array}{c}\text { Geometric mean } \\
\text { (CI) }\end{array}$ & $\begin{array}{c}\text { Standard deviation } \\
(\mathrm{Cl})\end{array}$ \\
\hline Artesunate & $31(100)$ & $0(0)$ & $0.2 / 3.6$ & $\begin{array}{c}0.73 \\
(0.38-1.08)\end{array}$ & $\begin{array}{c}0.95 \\
(0.76-1.27)\end{array}$ \\
\hline Amodiaquine & $22(71.0)$ & $9(29.0)$ & $2.0 / 162.0$ & $\begin{array}{c}30.69 \\
(14.18-47.20)\end{array}$ & $\begin{array}{c}45.00 \\
(35.96-60.15)\end{array}$ \\
\hline Chloroquine & $15(48.4)$ & $16(51.6)$ & $2.0 / 200.0$ & $\begin{array}{c}58.73 \\
(38.08-79.38)\end{array}$ & $\begin{array}{c}56.30 \\
(44.99-75.25)\end{array}$ \\
\hline Quinine & $25(80.6)$ & $6(19.4)$ & 15.0/990.0 & $\begin{array}{c}355.37 \\
(250.48-460.26)\end{array}$ & $\begin{array}{c}285.95 \\
(228.50-382.22)\end{array}$ \\
\hline
\end{tabular}

${ }^{*} \mathrm{C}_{50}$ threshold for resistance are amodiaquine $60 \mathrm{nM}$, chloroquine $100 \mathrm{nM}$ and quinine $800 \mathrm{nM}$. Studies on sensitivity cut-off point for artemisinin and its derivative is not conclusive yet but an $\mathrm{IC}_{50}$ of $20 \mathrm{nM}$ is considered high [28,29]. Thirty-eight (38) samples were tested, out of which 31 (81.6\%) were successfully phenotyped with the anti-malaria drugs. Test was successful when percentage of schizont to total parasite in drug-free control well was at least $10 \%$. Confidence interval $(\mathrm{Cl})$ is at 0.05 significance level.

were rare, while neither L263E nor S769N allele was observed. One sample harboured five mutations, another with four mutations while eight samples had three mutations each, and ten samples with two mutations each. Sequence comparisons of the pftctp gene revealed extreme conservation as all isolates exhibited the same identity.

Prevalence of genetic polymorphisms in pfmdr1 and pfcrt alleles

Sixty parasite isolates were successfully amplified for both $p f m d r 1$ and $p f c r t$ genes, with 34 isolates phenotyped. Fifteen $(25 \%)$ isolates harboured the N86Y mutation (TAT nucleotides) while 43/60 (71.7\%) with Y184F mutation (TTT nucleotides) in the pfmdr1 gene (Figure 2). Twenty-two (36.7\%) samples were double mutants and $30 / 60$ (50\%) had the single mutant Y184F. None of these mutants was found to be associated with drug response which was supported by Fisher's exact test (Table 5). A total of 29/60 (48.3\%) CVIET and 31/60 (51.7\%) CVMNK, which are chloroquine-resistant and chloroquine-sensitive genotypes respectively were identified at codons 72-76 of pfcrt gene. This was consistent with the in vitro culture but there was no particular association with artesunate response. This observation was corroborated by Fisher's exact test (Table 5). There was no observed correlation between pfATPase6 D638G and pfcrt K76T with Pearson's correlation coefficient value of -0.178 and Fisher's exact test of 0.738 at $p=0.05$.

\section{Discussion}

The use of oral artemisinin-based monotherapies alongside ACT is a common practice in Ghana [20], a situation that if not monitored and controlled threatens the

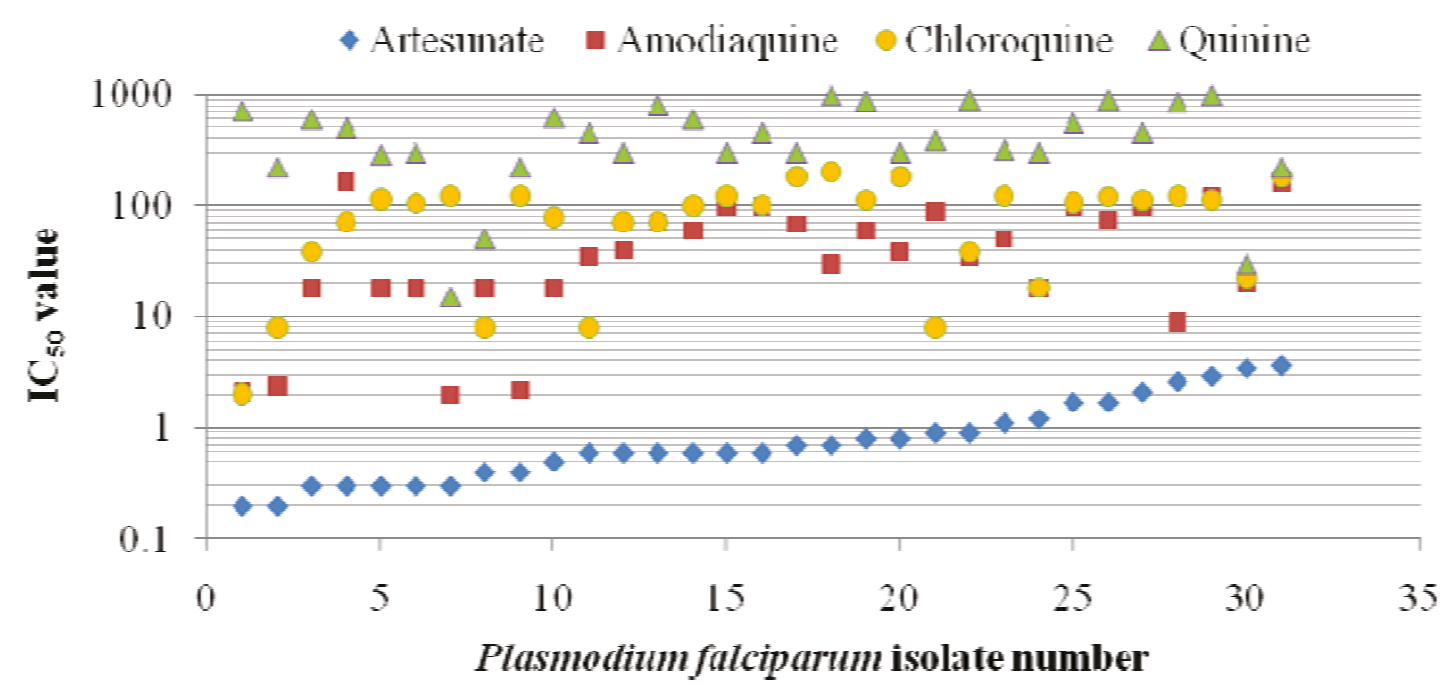

Figure 1 In vitro IC50 values for artesunate, amodiaquine, chloroquine and quinine for field isolates of Plasmodium falciparum. The isolates have been arranged in ascending order of artesunate IC50 values; thirty-eight isolates from patients diagnosed with uncomplicated malaria were used, out of which seven failed the tests due to poor growth/contamination. 
Table 3 Pearson's correlation coefficient $(r)$ between IC 50 values of the anti-malaria drugs

\begin{tabular}{lccc}
\hline Anti-malaria drugs & Pearson's $\boldsymbol{r}$ & Interpretation & $\boldsymbol{p}$ value \\
\hline artesunate vs. amodiaquine & 0.515 & Large & $<0.001$ \\
artesunate vs. chloroquine & 0.366 & Medium & $<0.001$ \\
artesunate vs. quinine & 0.281 & Small & $<0.001$ \\
amodiaquine vs. chloroquine & 0.308 & Medium & $<0.005$ \\
amodiaquine vs. quinine & 0.188 & Small & $<0.001$ \\
chloroquine vs. quinine & 0.144 & Small & $<0.001$ \\
\hline
\end{tabular}

Significance level was set at 0.05 , while the range for interpretation of correlation coefficient is as follows; None, 0.0 - 0.09; Small, 0.1 - 0.3; Medium, 0.3 0.5; Large, $0.5-1.0$

efficacy of the latter. In the latest World Malaria Report, WHO admonishes all endemic countries to be more vigilant in monitoring anti-malaria drug efficacy for early detection of artemisinin resistance [31]. Alam et al [32] reported on pfcrt, pfmdr1, dhps and dhfr mutations associated with chloroquine and sulphadoxine-pyrimethamine resistance and the microsatellite loci flanking these genes in P. falciparum isolates from Ghana. There is no report on pfATPase 6 genotype from this part of the world. In this study, we determined the prevalence of point mutations in pfATPase6, pftctp, pfmdr1, pfcrt genes and partly evaluated the susceptibility of $P$. falciparum parasites to artesunate, amodiaquine, chloroquine and quinine in vitro.

Table 4 SNPs and their corresponding amino acid point mutations in pfATPase6 gene, $N=68$

\begin{tabular}{lccc}
\hline SNP & Point mutation & Frequency (\%) & Artesunate $\mathbf{I C}_{\mathbf{5 0}}(\mathbf{n M})$ \\
\hline GGC & D639G & $34(50.0)$ & $0.2-3.6^{*}$ \\
AAA & E431K & $7(10.3)$ & $0.6-3.6$ \\
GAA & D443E & $5(7.4)$ & $0.6^{*}$ \\
CAA & M813Q & $5(7.4)$ & $0.6-0.9$ \\
CAT & Q622H & $3(4.4)$ & $0.3-3.6$ \\
GTA & L402V & $2(2.9)$ & $0.3-2.6$ \\
TTA & F414L & $2(2.9)$ & $0.4-0.8$ \\
AAT & D419N & $2(2.9)$ & 0.3 \\
TAT & C356Y & $1(1.5)$ & 1.4 \\
AAA & R377K & $1(1.5)$ & $\mathrm{NA}$ \\
AAA & E384K & $1(1.5)$ & $\mathrm{NA}$ \\
AAA & T403K & $1(1.5)$ & 0.2 \\
GAA & D405E & $1(1.5)$ & 1.7 \\
ACT & A425T & $1(1.5)$ & $\mathrm{NA}$ \\
AAA & E432K & $1(1.5)$ & $\mathrm{NA}$ \\
TCT & A630S & $1(1.5)$ & $\mathrm{NA}$ \\
GGT & C645G & $1(1.5)$ & 0.5 \\
GGA & E696G & $1(1.5)$ & $\mathrm{NA}$ \\
AAA & E710K & $1(1.5)$ & 0.4 \\
GGT & D734G & $1(1.5)$ & $\mathrm{NA}$ \\
\hline
\end{tabular}

*Some isolates of the corresponding nucleotide were not phenotyped, just as NA (not applicable) represents isolates that were not phenotyped.
Table 5 Fisher's exact test of association between polymorphisms and in vitro drug response, $N=31$

\begin{tabular}{lc}
\hline Polymorphism vs. drug & $\boldsymbol{p}$ value \\
\hline pfcrt (K76T) vs. chloroquine & 0.001 \\
pfATPase6 (D639G) vs. artesunate & 0.423 \\
pfcrt (K76T) vs. artesunate & 1.000 \\
pfmdr1 (N86Y) vs. artesunate & 1.000 \\
pfmdr1 (Y184F) vs. artesunate & 1.000 \\
pfmdr1 (N86Y) vs. chloroquine & 1.000 \\
pfmdr1 (Y184F) vs. chloroquine & 0.104 \\
pfmdr1 (N86Y) vs. amodiaquine & 1.000 \\
pfmdr1 (Y184F) vs. amodiaquine & 0.253 \\
pfmdr1 (N86Y) vs. quinine & 1.000 \\
pfmdr1 (Y184F) vs. quinine & 1.000 \\
pfmdr1 (double mutant) vs. artesunate & 0.577 \\
pfmdr1 (double mutant) vs. chloroquine & 1.000 \\
pfmdr1 (double mutant) vs. amodiaquine & 0.630 \\
pfmdr1 (double mutant) vs. quinine & 1.000 \\
\hline
\end{tabular}

Studies have shown that parasites from the African continent appear to be more susceptible to artemisinin derivatives $[28,33,34]$. In this study, all field isolates of $P$. falciparum that were tested exhibited satisfactory in vitro response to artesunate, while more than half were resistant to chloroquine. What is more important is the presence of parasite isolates that are resistant to amodiaquine in the phase of continual use of oral artemisininbased monotherapies. Ferreira et al [28] in their study observed a strong correlation between artesunate and amodiaquine; its significance in terms of factors that lead to sensitivity must be studied since this observation was replicated in our study. Oduro et al [35] reported on reduced cure rate of amodiaquine in northern Ghana. While it has been observed that persons infected with artemisinin resistant parasites could be cured by ACT, cure rate largely depended on efficacy of the non-artemisinin component of the combination [31]. This calls for speedy action on withdrawal of oral artemisinin-based monotherapies from the Ghanaian market. For effective use of these drugs in the control of malaria, there is the need for generation of molecular epidemiological data, ideally before the introduction of such drugs since mutations could be selected by previous drug pressure. Evaluation of polymorphisms in potential candidate genes of drug resistance is of utmost importance to establishing their role in modulating drug response, and to predicting epidemiological dynamics of resistance.

The limitation to this study was that polymorphisms in the pfATPase6 gene was investigated after five years of drug (artemisinin and its derivatives) pressure in Ghana; nonetheless, this study presents a picture in time since there is no report of artemisinin resistance in Ghanaian isolates. This study therefore describes for the first 


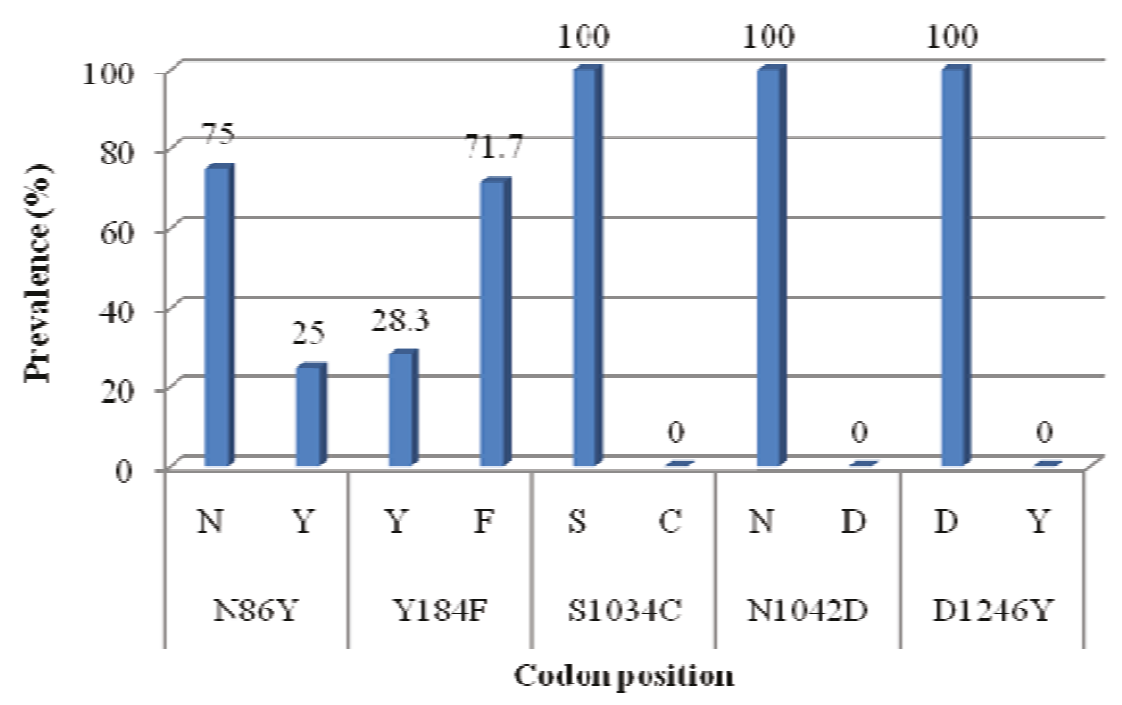

Figure 2 Prevalence of genetic polymorphisms in the pfmdr1 gene, $\mathbf{N}=\mathbf{6 0}$. All N86Y mutants possessed the TAT nucleotides while all Y184F harboured the TTT nucleotides. Twenty-two (36.7\%) samples were double mutants and 30 (50\%) samples had the single mutant Y184F.

time, polymorphisms in pfATPase6 gene in such isolates. By using PCR sequencing assay, neither L263E nor S769N point mutation was observed; and this is consistent with the in vitro micro-test results. A total of twenty point mutations were observed in this gene, confirming its molecular diversity than previously demonstrated $[15,36,37]$; these however, may be spontaneous mutations since their role in artemisinin sensitivity is not yet defined. D639G mutation was observed in about half of the parasite isolates, and thus appears to be fixed in the parasite population. This mutant is supposed to be positioned in the cytosolic region located between transmembrane domains 5 and 6 , albeit its biological significance is difficult to forecast in the absence of functional analysis [29].

Even though studies have shown the involvement of the malaria parasite pftctp gene in artemisinin activity, our present result confirms its extreme conservation, and thus not a strong candidate for resistance to artemisinin and its derivatives due to the fact that it is not under major selective drug pressure [14,29]. Studies have suggested that mutant haplotypes of $p f m d r 1$ and pfcrt genes in some isolates conferred chloroquine resistance [38,39], but however increase parasite susceptibility to artemisinin $[17,18]$. Our study revealed the presence of two mutations in the $p f m d r 1$ gene and K76T allele in the pfcrt gene; but they had no part in the modulation of artesunate response as the lowest and highest artesunate $\mathrm{IC}_{50}$ values corresponded to parasite isolates with pfcrt K76T. This was corroborated by Fisher's exact test. Afonso et al [40] in their study observed that malaria parasites, such as Plasmodium chabaudi, can develop stable resistance to artemisinin but lack mutations in candidate genes including atp6, tctp, $m d r 1$ and $\operatorname{cg} 10$.

More than half of the parasite isolates were resistant to chloroquine after five years of its proscription in Ghana, which is a reflection of our molecular results but at variance to the Malawian situation where sensitive isolates were recovered after stopping the use of chloroquine [21,22]. The K76T allele was strongly associated with this behaviour, which was confirmed by Fisher's exact test. This may be due to the persistent use of chloroquine in some parts of Ghana [20].

\section{Conclusion}

Plasmodium falciparum isolates from southern Ghana showed no improvement in susceptibility to chloroquine, but they exhibited satisfactory in vitro response to artesunate. No L263E and S769N mutations in the SERCA-type PfATPase6 were observed, albeit evidence is clear on the greater molecular diversity of PfATPase6 than previously demonstrated as twenty mutations were detected with D639G appearing to be fixed in this parasite population. Whereas these mutations may be spontaneous and as such without any particular role in the parasites response to artemisinin, continual monitoring of $P$. falciparum susceptibility to artemisinin is welcome.

\section{Acknowledgements}

Our deepest gratitude goes to Yvonne Aryeetey, Sampson Otoo, Dickson Osabutey, Emmanuel K. Dickson, Natalia S. Awuni and Michelle Adimazoya who helped with the sample collection and the culture work. We equally acknowledge the diverse contributions of Henrietta Terko Doe, Francis Ekow Dennis and Dr. Takenori Seki, as well as all medical personnel who helped with the sample collection. We appreciate the invaluable contributions and support of the chiefs and elders of the study communities, and all persons 
who provided blood samples for the study. This work was supported by a grant of Japan Initiative for Global Research Network on Infectious Diseases, and the Ministry of Education, Culture, Sports, Science and Technology (MEXT), Japan. It was also supported by a grant from the Ministry of Health, Welfare and Labour, Japan (H22 Seisaku Soyaku-003).

\section{Author details}

${ }^{1}$ Section of Environmental Parasitology, Department of International Health Development, Tokyo Medical and Dental University, 5-45 Yushima 1-chome, Bunkyo-ku, Tokyo 113-8519, Japan. ${ }^{2}$ Parasitology Department, Noguchi Memorial Institute for Medical Research, P.O. Box LG 581, University of Ghana, Accra, Ghana. ${ }^{3}$ Immunology Department, Noguchi Memorial Institute for Medical Research, P.O. Box LG 581, University of Ghana, Accra, Ghana. ${ }^{4}$ Department of Parasitology, National Institute of Infectious Diseases, 23-1 Toyama 1-chome, Shinjuku-ku, Tokyo 162-8640, Japan.

\section{Authors' contributions}

BKB and NO conceived the idea, while BKB, IA, TS, JO, WKA and JHNO performed the field work. BKB, IA, TS, JO, JHNO, HA, MFO and NA did the in vitro drug assessment test while BKB and TK did the molecular work. NO, MDW and DAB were involved in all stages. BKB wrote the manuscript, which was read and approved by all authors.

\section{Competing interests}

The authors declare that they have no competing interests.

Received: 3 May 2011 Accepted: 11 July 2011 Published: 11 July 2011

\section{References}

1. World Health Organization: World Malaria Report 2008 [http://whqlibdoc. who.int/publications/2008/9789241563697_eng.pdf], WHO/HTM/GMP/ 2008.1.

2. Afari EA, Akanmori BD, Nakano T, Ofori-Adjei D: Plasmodium falciparum: sensitivity to chloroquine in vivo in three ecological zones in Ghana. Trans R Soc Trop Med Hyg 1992, 86:231-232.

3. Spencer HC, Watkins WW, Sixsmith DG, Koech DK: Response of Plasmodium falciparum to dihydrofolate reductase inhibitors in Malindi, Kenya. Trans R Soc Trop Med Hyg 1986, 80:201-203.

4. Akompong TS, Eksi S, Williamson K, Haldar K: Gametocytocidal activity and synergistic interactions of riboflavin with standard anti-malarial drugs against growth of Plasmodium falciparum in vitro. Antimicrob Agents Chemother 2000, 44:3107-3111.

5. Ubalee R, Songthammawat D, Na-Bangchang K, Tan-ariya P, Karbwang J: Ex vivo blood schizontocidal activities of artemisinin derivatives against Plasmodium falciparum. Southeast Asian J Trop Med Public Health 1999, 30:225-231.

6. World Health Organization: Framework for developing, implementing and updating national antimalaria treatment policy: A guide for country malaria control programmes [http://afrolib.afro.who.int/documents/2003/english/ framedrugp.pdf], AFR/MAL/03.02.

7. Alker AP, Lim P, Sem R, Shah NK, Yi P, Bouth DM, Tsuyuoka R, Maguire JD, Fandeur T, Ariey F, Wongsrichanalai C, Meshnick SR: Pfmdr1 and in vivo resistance to artesunate-mefloquine in falciparum malaria on the Cambodian-Thai border. Am J Trop Med Hyg 2007, 76:641-647.

8. Dondorp AM, Nosten F, Yi P, Das D, Phyo AP, Tarning J, Lwin KM, Ariey F, Hanpithakpong W, Lee SJ, Ringwald P, Silamut K, Imwong M, Chotivanich K, Lim P, Herdman T, An SS, Yeung S, Singhasivanon P, Day NP, Lindegardh N, Socheat D, White NJ: Artemisinin resistance in Plasmodium falciparum malaria. N Engl J Med 2009, 361:455-467.

9. Yang H, Liu D, Yang Y, Fan B, Yang P, Li X, Li C, Dong Y, Yang C: Changes in susceptibility of Plasmodium falciparum to artesunate in vitro in Yunnan Province, China. Trans R Soc Trop Med Hyg 2003, 97:226-228.

10. Wernsdorfer WH: The development and spread of drug-resistant malaria. Parasitol Today 1991, 7:297-303

11. Bhisutthibhan J, Pan XQ, Hossler PA, Walker DJ, Yowell CA, Carlton J, Dame JB, Meshnick SR: The Plasmodium falciparum translationally controlled tumour protein homologue and its reaction with the antimalarial drug artemisinin. J Biol Chem 1998, 273:16192-16198.

12. Eckstein-Ludwig U, Webb RJ, Van Goethem ID, East JM, Lee AG, Kimura M, O'Neill PM, Bray PG, Ward SA, Krishna S: Artemisinins target the SERCA of Plasmodium falciparum. Nature 2003, 424:957-961.
13. Uhlemann AC, Cameron A, Eckstein-Ludwig U, Fischbarg J, Iserovich P, Zuniga FA, East M, Lee A, Brady L, Haynes RK, Krishna S: A single amino acid residue can determine the sensitivity of SERCAs to artemisinins. Nat Struct Mol Biol 2005, 12:628-629.

14. Jambou R, Legrand E, Niang M, Khim N, Lim P, Volney B, Ekala MT, Bouchier C, Esterre P, Fandeur T, Mercereau-Puijalon O: Resistance of Plasmodium falciparum field isolates to in-vitro artemether and point mutations of the SERCA-type PfATPase6. Lancet 2005, 366:1960-1963.

15. Dahlstrom S, Veiga MI, Ferreira P, Martensson A, Kaneko A, Andersson B, Bjorkman A, Gil JP: Diversity of the sarco/endoplasmic reticulum $\mathrm{Ca}^{2}$ ${ }^{+}$-ATPase orthologue of Plasmodium falciparum (PfATP6). Infect Genet Evol 2008, 8:340-345.

16. Ibrahim ML, Khim N, Adam HH, Ariey F, Duchemin J-B: Polymorphism of PfATPase in Niger: detection of three new point mutations. Malar J 2009, 8:28.

17. Sidhu $A B$, Verdier-Pinard D, Fidock DA: Chloroquine resistance in Plasmodium falciparum malaria parasites conferred by Pfcrt mutations. Science 2002, 298:210-213.

18. Sidhu ABS, Uhlemann A-C, Valderramos SG, Valderramos J-C, Krishna S, Fidock DA: Decreasing pfmdr1 copy number in Plasmodium falciparum malaria heightens susceptibility to mefloquine, lumefantrine, halofantrine, quinine, and artemisinin. J Infect Dis 2006, 194:528-535.

19. Koram KA, Abuaku B, Duah N, Quarshie N: Comparative efficacy of antimalarial drugs including ACTs in the treatment of uncomplicated malaria among children under 5 years in Ghana. Acta Trop 2005, 95:194-203.

20. Kwansa-Bentum B, Ayi I, Suzuki T, Otchere J, Kumagai T, Anyan WK, Asahi H, Akao N, Wilson MD, Boakye DA, Ohta N: Administrative practices of health professionals and use of artesunate-amodiaquine by community members for treating uncomplicated malaria in southern Ghana: implications for artemisinin-based combination therapy deployment. Trop Med Int Health

21. Kublin JG, Cortese JF, Njunju EM, Mukadam RA, Wirima JJ, Kazembe PN, Djimde AA, Kouriba B, Taylor TE, Plowe CV: Reemergence of chloroquinesensitive Plasmodium falciparum malaria after cessation of chloroquine use in Malawi. J Infect Dis 2003, 187:1870-1875.

22. Mita T, Kaneko A, Lum JK, Bwijo B, Takechi M, Zungu IL, Tsukahara T, Tanabe K, Kobayakawa T, Bjorkman A: Recovery of chloroquine sensitive and low prevalence of the Plasmodium falciparum chloroquine resistance transporter gene mutation K $76 \mathrm{~T}$ following the discontinuation of chloroquine use in Malawi. Am J Trop Med Hyg 2003, 68:413-415.

23. Appawu MA, Baffoe-Wilmot A, Afari EA, Dunyo S, Koram : Malaria vector studies in two ecological zones in southern Ghana. Afr Entomol 2001, 9:59-65.

24. Okoye PN, Wilson MD, Boakye DA, Brown CA: Impact of the Okyereko irrigation project in Ghana on the risk of human malaria infection by Anopheles species (Diptera: Culicidae). Afr Entomol 2005, 13:249-253.

25. Ofori MF, Dodoo D, Staalsoe T, Kurtzhals JA, Koram K, Theander TG, Akanmori BD, Hviid L: Malaria-Induced Acquisition of Antibodies to Plasmodium falciparum Variant Surface Antigens. Infect Immun 2002, 70:2982-2988.

26. Asahi H, Kanazawa T, Hirayama N, Kajihara Y: Investigating serum factors promoting erythrocytic growth of Plasmodium falciparum. Exp Parasitol 2005, 109:7-15.

27. World Health Organization: In vitro micro-test (Mark III) for the assessment of the response of Plasmodium falciparum to chloroquine, mefloquine, quinine, amodiaquine, sulfadoxine/pyrimethamine and artemisinin: Instructions for use of the in vitro micro-test kit (Mark III) CTD/MAL/97.20.[http://whqlibdoc.who.int/hq/2001/a76873.pdf].

28. Ferreira ID, Lopes D, Martinelli A, Ferreira C, do Rosario VE, Cravo P: In vitro assessment of artesunate, artemether and amodiaquine susceptibility and molecular analysis of putative resistance-associated mutations of Plasmodium falciparum from Sao Tome and Principe. Trop Med Int Health 2007, 12:353-362.

29. Ferreira ID, Martinelli $A$, Rodrigues $L A$, do Carmo EL, do Rosario VE, Povoa MM, Cravo P: Plasmodium falciparum from Para state (Brazil) shows satisfactory in vitro response to artemisinin derivatives and absence of the S769N mutation in the SERCA-type PfATPase6. Trop Med Int Health 2008, 13:199-207.

30. Kumagai T, Furushima-Shimogawara R, Ohmae H, Wang TP, Lu S, Chen R, Wen L, Ohta N: Detection of early and single infections of Schistosoma 
japonicum in the intermediate host snail, Oncomelania hupensis, by PCR and Loop-mediated isothermal amplification (LAMP) assay. Am J Trop Med Hyg 2010, 83:542-548.

31. World Health Organization: World Malaria Report 2010. WHO Global Malaria Program [http://www.who.int/malaria/world_malaria_report_2010/ worldmalariareport2010.pdf].

32. Alam MdT, de Souza DK, Vinayak S, Griffing Sm, Poe AC, Duah NO, Ghansah A, Asamoah K, Slutcker L, Wilson MD, Barnwell JW, Udhayakumar V, Koram KA: Selective sweeps and genetic lineages of Plasmodium falciparum drug-resistant alleles in Ghana. J Infect Dis 2011, 203:220-227.

33. Henry M, Diallo I, Bordes J, Ka S, Pradines B, Diatta B, M'Baye PS, Sane M, Thiam M, Gueye PM, Wade B, Touze JE, Debonne JM, Rogier C, Fusai T: Urban malaria in Dakar, Senegal: chemosusceptibility and genetic diversity of Plasmodium falciparum isolates. Am J Trop Med Hyg 2006, 75:146-151.

34. Ramharter M, Burkhardt D, Nemeth J, Adegnika AA, Kremsner PG: In vitro activity of artemisone compared with artesunate against Plasmodium falciparum. Am J Trop Med Hyg 2006, 75:637-639.

35. Oduro AR, Anyorigiya T, Koram K, Anto F, Atobrah P, Hodgson A: Amodiaquine in future combination treatment of malaria in Ghana. Trop Doct 2007, 37:154-156.

36. Menegon M, Sannella AR, Majori G, Severini C: Detection of novel point mutations in the Plasmodium falciparum ATPase6 candidate gene for resistance to artemisinins. Parasitol Int 2008, 57:233-235.

37. Jambou R, Martinelli A, Pinto J, Gribaldo S, Legrand E, Niang M, Kim N, Pharath L, Volnay B, Ekala MT, Bouchier C, Fandeur T, Berzosa P, Benito A, Ferreira ID, Ferreira C, Vieira PP, Alecrim MG, Mercereau-Puijalon O, Cravo P: Geographic structuring of the Plasmodium falciparum sarco(endo) plasmic reticulum $\mathrm{Ca}^{2+}$ ATPase (PfSERCA) gene diversity. PLoS One 2010, 5:e9424.

38. Cowman AF, Karez S, Galatis D, Culvenor JG: A P-glycoprotein homologue of Plasmodium falciparum is localized on the digestive vacuole. J Cell Biol 1991, 113:1033-1042.

39. Fidock DA, Nomura T, Talley AK, Cooper RA, Dzekunov SM, Ferdig MT, Ursos LM, Sidhu AB, Naude B, Deitsch KW, Su XZ, Wootton JC, Roepe PD, Wellems TE: Mutations in the $P$. falciparum digestive vacuole transmembrane protein Pfcrt and evidence for their role in chloroquine resistance. Mol Cell 2000, 6:861-871.

40. Afonso A, Hunt P, Cheesman S, Alves AC, Cunha CV, do Rosario V, Cravo P: Malaria parasites can develop stable resistance to artemisinin but lack mutations in candidate genes atp6 (encoding the sarcoplasmic and endoplasmic reticulum $\mathrm{Ca}^{2+}$ ATPase), tctp, mdr1, and cg10. Antimicrob Agents Chemother 2006, 50:480-489.

doi:10.1186/1475-2875-10-187

Cite this article as: Kwansa-Bentum et al:: Plasmodium falciparum isolates from southern Ghana exhibit polymorphisms in the SERCA-type PfATPase6 though sensitive to artesunate in vitro. Malaria Journal 2011 10:187

\section{Submit your next manuscript to BioMed Central and take full advantage of:}

- Convenient online submission

- Thorough peer review

- No space constraints or color figure charges

- Immediate publication on acceptance

- Inclusion in PubMed, CAS, Scopus and Google Scholar

- Research which is freely available for redistribution

Submit your manuscript at www.biomedcentral.com/submit 